\title{
The value of the anatomical features of the sigmoid colon in developing sigmoid volvulus Sopuev A. ${ }^{1}$, Isaev D. ${ }^{2}$, Sydygaliev K. ${ }^{3}$, Sydykov N. ${ }^{4}$, Mambetov A. ${ }^{5}$ (Republic of Kyrgyzstan) \\ Значение анатомических особенностей сигмовидной кишки в развитии ее заворота

\author{
Сопуев А. А. ${ }^{1}$ Исаев Д. к. ${ }^{2}$, Сыдыгалиев К. С. ${ }^{3}$, Сыдыков Н. ж. ${ }^{4}$, \\ Мамбетов А. К.
}

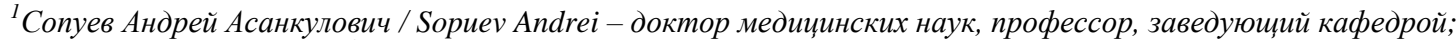

${ }^{2}$ Исаев Данияр Канатбекович / Isaev Daniyar - аспирант;

${ }^{3}$ Сыдыгалиев Кылычєек Сулкайдарович / Sydygaliev Kylychbek - доктор медицинских наук, доцент, кафедра госпитальной хирургии, Кыргызская Государственная медицинская академия;

${ }^{4}$ Сыдылков Нурлан Женишбекович / Sydykov Nurlan-кандидат медичинских наук, заведуюший отделением, приемное отделение, Наииональный хирургический центтр;

${ }_{5}^{5}$ Мамбетов Адыл Карагулович / Mambetov Adil - кандидат медичинских наук, ассистент, кафедра госпитальной хирургии, Кыргызская Государственная медицинская академия, г. Бишкек, Кыргызская Республика
}

Аннотация: в работе проведено определение роли анатомических особенностей сигмовидной кишки и ее брыжейки в развитии заворота сигмовидной кишки.

Abstract: in a study carried out to define the role of anatomical features of the sigmoid colon and the mesosigmoid in the development of the sigmoid volvulus.

Ключевые слова: сигмовидная кишка, заворот.

Keywords: sigmoid colon, sigmoid volvulus.

Заворот сигмовидной кишки (ЗСК) является опасным для жизни состоянием, которое возникает в результате вращения сигмовидной кишки вдоль оси своей брыжейки и приводит к обструкции просвета кишечной петли [3].

ЗСК является частой причиной кишечной непроходимости $(10 \%-13 \%)$ и связана с высоким уровнем осложнений и смертности.

Ранее проведенные исследования показали, что длинная брыжейка сигмовидной кишки (БСК) является анатомическим фактором предрасположенности определенных групп людей к развитию ЗСК [3, 4]. Длинная БСК, как полагают, бывает врожденной или приобретенной, вследствие хронических запоров [2]. На сегодняшний день проводились только недостаточно контролируемые перспективные исследования по изучению роли особенностей анатомии сигмовидной кишки при развитии ЗСК.

Таким образом, целью проводимого исследования явилось определение роли анатомических особенностей сигмовидной кишки и ее брыжейки в развитии ЗСК в перспективном исследовании случайконтроль.

Материал и результаты исследования.

В исследование было включено 38 пациентов с соответствующими параметрами (26 случаев заворота сигмовидной кишки и 12 случаев из контрольной группы). Из них, лица мужского пола количественно значительно превалировали над лицами женского пола как в основной группе $(20 / 23,87 \%)$, так и в контрольной группе $(10 / 12,83 \%)$. Средний возраст пациентов в основной $(54,7$ лет) и контрольной $(48,4$ лет) группах не имел статистически значимых различий.

Средние величины длины (p1) сигмовидной кишки, размеров окружности у проксимального (p3) и дистального (p4) ее концов, апекса (p2) сигмовидной кишки имели более значительные величины у больных из основной группы $(\mathrm{p}<0,05)$ по сравнению с контрольной. В случаях заворота сигмовидной кишки имели место более длинная брыжейка сигмовидной кишки (р5) $(P<0,05)$ и ее максимальная ширина (р6) $(P<0,05)$. Ширина корня брыжейки сигмовидной кишки (р7) не отличалась между двумя группами (P = NS) (Таблица 1).

Таблица 1. Характеристика анатомических особенностей сигмовидной кишки

\begin{tabular}{|c|c|c|c|}
\hline Анатомические параметры & $\begin{array}{c}\text { Основная } \\
\text { группа }\end{array}$ & Контрольная группа & Р \\
\hline Длина сигмовидной кишки (p1) & $\begin{array}{c}85,8 \\
(80,5-91,1)\end{array}$ & $\begin{array}{c}40,2 \\
(36,9-43,4)\end{array}$ & $<0,001$ \\
\hline Окружность сигмовидной кишки, апекс (p2) & $\begin{array}{c}19,1 \\
(16,7-21,4)\end{array}$ & $\begin{array}{c}7,2 \\
(6,2-8,1)\end{array}$ & $<0,001$ \\
\hline
\end{tabular}




\begin{tabular}{|c|c|c|c|}
\hline Анатомические параметры & $\begin{array}{l}\text { Основная } \\
\text { группа }\end{array}$ & Контрольная группа & $\mathbf{P}$ \\
\hline $\begin{array}{c}\text { Окружность сигмовидной кишки, } \\
\text { проксимальных (р3) }\end{array}$ & $\begin{array}{c}9,3 \\
(8,5-10,1)\end{array}$ & $\begin{array}{c}7,8 \\
(6,5-9,0)\end{array}$ & 0,019 \\
\hline $\begin{array}{c}\text { Окружность сигмовидной кишки, дистальной } \\
(\mathrm{P} 4)\end{array}$ & $\begin{array}{c}11,6 \\
(10,6-12,5) \\
\end{array}$ & $\begin{array}{c}7,4 \\
(6,4-8,3) \\
\end{array}$ & $<0,001$ \\
\hline Длина мезосигмы (р5) & $\begin{array}{c}27,3 \\
(25,3-29,3)\end{array}$ & $\begin{array}{c}13,1 \\
(11,2-15,1)\end{array}$ & $<0,001$ \\
\hline Максимальная ширина мезосигмы (Р6) & $\begin{array}{c}12,8 \\
(10,5-15,1)\end{array}$ & $\begin{array}{c}7,6 \\
(6,5-8,8)\end{array}$ & $<0,001$ \\
\hline Ширина мезосигмы в корне (Р7) & $\begin{array}{c}7,9 \\
(7,1-8,7)\end{array}$ & $\begin{array}{c}7,1 \\
(6,2-8,0) \\
\end{array}$ & 0,24 \\
\hline $\begin{array}{c}\text { Отношение мезосигмы, максимальная ширина / } \\
\text { длина (P6 / Р5) }\end{array}$ & $\begin{array}{c}0,60 \\
(0,45-0,74) \\
\end{array}$ & $\begin{array}{c}0,49 \\
(0,43-0,54) \\
\end{array}$ & 0,079 \\
\hline $\begin{array}{l}\text { Отношение мезосигмы, ширина корня / длина } \\
\text { (Р7 / p5) }\end{array}$ & $\begin{array}{c}0,59 \\
(0,40-0,78) \\
\end{array}$ & $\begin{array}{c}0,29 \\
(0,26-0,32) \\
\end{array}$ & $<0,001$ \\
\hline $\begin{array}{c}\text { Отношение мезосигмы, ширина корневой / } \\
\text { максимальная ширина (Р7 / P6) }\end{array}$ & $\begin{array}{c}0,99 \\
(0,85-1,14)\end{array}$ & $\begin{array}{c}0,63 \\
(0,56-0,70)\end{array}$ & $<0,001$ \\
\hline
\end{tabular}

Также производился расчет отношения длины (р5), максимальной ширины (p6) и ширины корня (p7) брыжейки сигмовидной кишки. Соотношение между максимальной шириной и длиной брыжейки сигмовидной кишки (p6/p5) не имело различий между исследуемыми группами $(P=\mathrm{NS})$, а это означает, что ободочная кишка с более длинной мезосигмой также имела и максимальную ширину мезосигмы в обоих исследуемых группах. Существенная разница между случаями заворота сигмовидной кишки и контрольной группой $(\mathrm{p}<0,05)$ была выявлена при сравнении отношения ширины корня к длине мезосигмы (P7 / P5) и отношение ширины корня к максимальной ширине мезосигмы (P7/P6). Другими словами, обследование пациентов с заворотом сигмовидной кишки показало относительно более протяженные длина и максимальная ширина мезосигмы по отношению к ширине корня мезосигмы по сравнению с размерами мезосигмы в контрольной группе.

Обсуждение.

Результаты исследования показали, что имеет место значительная разница в анатомии сигмовидной кишки и ее мезосигмы у пациентов с заворотом сигмовидной кишки и у лиц контрольной группы. Важно подчеркнуть, что к завороту сигмовидной кишки предрасполагает перекручивание длинной и широкой мезосигмы вокруг узкого ее корня. Также, несмотря на то, что, ширина корня мезосигмы была конвергентна в обоих исследуемых группах, отношение корня мезосигмы к ее максимальной ширине и к ее длине меньше в случаях заворота сигмовидной кишки. Другими словами, ширина корня мезосигмы в случаях заворота сигмовидной кишки лишь относительно меньше по отношению к длине и максимальной ширине мезосигмы, абсолютные величины ширины корня мезосигмы не отличались в основной и контрольной группах.

Таким образом, полученные результаты опровергают общепринятый механизм развития заворота сигмовидной кишки [1], подразумевающий узкую мезосигму и избыточную длину сигмовидной кишки $[5,6]$. Хотя в нашем исследовании были случаи избыточной мезосигмы (более длинная мезосигма с большой максимальной шириной), мы не обнаружили корреляции между узкой мезосигмой и сигмовидным заворотом. Ширина корня мезосигмы не отличалась в обоих исследуемых группах.

В этом проспективном исследовании представлены доказательства анатомической предрасположенности к завороту сигмовидной кишки и проясняются конкретные анатомические особенности. Результаты проведенного исследования коррелируют с исследованиями Bhatnagar et al. [2], который при изучении анатомии ободочной кишки разделил ее на два варианта. В одном варианте это долихомезоколон, в котором брыжейка ободочной кишки длиннее, чем шире; брахимезоколон, при которой брыжейка шире, чем длиннее. Долихомезоколон чаще встречается среди лиц мужского пола. Брахимезоколон чаще встречается среди лиц женского пола. Авторы предположили, что более высокая частота заворота сигмовидной кишки среди мужчин, по сравнению с женщинами, может быть частично связана из-за анатомической разницы.

Таким образом, заворот сигмовидной кишки более связан с длинной и широкой мезосигмой, чем с ее узким корнем. Другие детерминанты в этиопатогенезе заворота сигмовидной кишки еще предстоит дополнительно выяснить (роль диету, голодания и различных эндемичных районов). 


\section{Лuтература}

1. Ballantyne G. H. Review of sigmoid volvulus: History and results of treatment. // Dis Colon Rectum, 1982. № 25. P. 494-501.

2. Bhatnagar B. N., Sharma C. L., Gupta S. N., Mathur M. M., Reddy D. C. Study on the anatomical dimensions of the human sigmoid colon. // Clin Anat., 2004. № 17. P. 236-243.

3. Udezue N. O. Sigmoid volvulus in Kaduna, Nigeria. // Dis Colon Rectum., 1990. № 33. P. 647-649.

4. Vaez-Zadeh K., Dutz W. Ileosigmoid knotting. // Ann Surg., 1970. T. 172. P. 1027-1033.

5. Мамакеев М. М., Сопуев А. А., Салибаев О. А. Измерение скорости распространения поверхностных акустических волн в прогнозировании и диагностике течения раневого процесса // Хирургия. Журнал им. Н. И. Пирогова, 2000. № 1. С. 54-55.

6. Сопуев А.А., Абдиев А.Ш., Калжикеев А. А., Сыдыков Н.Ж., Мамбетов А. А. Профилактическое дренирование брюшной полости после операций на дистальных отделах ЖКТ. // Проблемы современной науки и образования, 2016. № 13 (55). С. 129-132. 